\title{
Entropy
}

ISSN 1099-4300

(C) 2003 by MDPI

www.mdpi.org/entropy

\section{Information Seen as Part of the Development of Living Intelligence: the Five-Leveled Cybersemiotic Framework for FIS $^{1}$}

\section{Søren Brier}

Dept. of Economics and Natural Resources, Rolighedsvej 23, DK-1958 Frederiksberg C, Denmark E-mail: sbr@kvl.dk, URL: http://www.flec.kvl.dk/personalprofile.asp?id=sbr\&p=engelsk

Received: 10 January 2003 / Accepted: 12 February 2003 / Published: 26 June 2003

\begin{abstract}
It is argued that a true transdisciplinary information science going from physical information to phenomenological understanding needs a metaphysical framework. Three different kinds of causality are implied: efficient, formal and final. And at least five different levels of existence are needed: 1 . The quantum vacuum fields with entangled causation. 2. The physical level with is energy and force-based efficient causation. 3 . The informational-chemical level with its formal causation based on pattern fitting. 4. The biological-semiotic level with its non-conscious final causation and 5. The social-linguistic level of self-consciousness with its conscious goal-oriented final causation. To integrate these consistently in an evolutionary theory as emergent levels, neither mechanical determinism nor complexity theory are sufficient because they cannot be a foundation for a theory of lived meaning. C. S. Peirce's triadic semiotic philosophy combined with a cybernetic and systemic view, like N. Luhmann's, could create the framework I call Cybersemiotics.
\end{abstract}

Keywords: Information Science, Biosemiotics, Cybersemiotics, Theory of Meaning, C. S. Peirce's Philosophy, Theory of Consciousness.

\section{Introduction}

I do not think that we can make a Foundation for a Transdisciplinary Information Science (TFIS) without relating it to theories of cognition, communication, mind and meaning on one hand, and classical science plus a theory of evolution on the other [1]. 
As Prigogine and Stengers have argued, one cannot base a through-going evolutionary theory from the physical and the chemical level, up to the level of living organisms on a mechanistic foundation [34]. It has a least to be some kind of complexity theory that accepts chance as real. This view is supported by the semiotician Peirce [1].

We have rather good explanations of how the physiological processes influence mental experiences, but we have no idea, whatsoever, of how mental decision based on free will can have any causal influence on our physiology. Thus we need to integrate first persons experience into a theory of information, meaning and nature if we want to capture the process of understanding and interpretation in human communication and in animal cognition and communication [1]. This means that we need internal consistency in our evolutionary theory going from matter to human first person social language-borne conscious life.

Therefore, I do not believe that a functionalistic information-processing paradigm with a basis in an objective statistical information-concept, in itself, is sufficient to be the frame encompassing the phenomenological aspects of meaning and mind. A theory of emergence like Kaufman's [23] or Maturana and Varela's [27] on autopoiesis cannot work properly on this physicalistic basis [5]. I know that many supporters of the process of emergence hope to be able to use to explain how new qualities arise out of matter such as life and mind. But so far emergence is just a concept for these qualitative shift - phase shifts to some - it is not a causal explanation. For example, as far as we know, a brain is necessary to have consciousness, but we cannot show that the brain creates consciousness.

1. Thus we need a new, broader and more profound foundation. We cannot just add information theory on top of the old mechanistic foundation, or a physicalistic foundation improved by complexity theory or random dynamics [29], as none of these theories includes a theory of the emergence of life, meaning and language.

2. We need some kind of reflective metaphysical frame going beyond the Plato-inspired mathematical determinism in physics that is also the source of much thinking in cognitive science and artificial intelligence. It lacks a profound theory of the relation between life and meaning.

3. At the same time such a framework has to be able to respect the nature of the various subject areas and their specific types of knowledge that we have developed within the sciences and humanities. This is an aspect that systems theory has worked with for quite a long time in the terms of different ontological levels and types of emergence, as Emmeche et. al. have pointed out [16].

Let me support my claim concerning the importance of combining information theory with a theory of first person experience, with a quote from a discussion in Journal of Consciousness Science. Here Velmans discusses the problem of science lacking a theory of mental causation on the physiological levels [40]:

"In everyday life we take it for granted that we have conscious control of some of our actions and that the part of us that exercises control is the conscious mind. Psychosomatic medicine also assumes that the conscious mind can affect body states, and this is supported by evidence that the use of imagery, hypnosis, biofeedback and other "mental interventions" can be therapeutic in a variety of medical conditions. However, there is no accepted theory of mind/body interaction and this has had a 
detrimental effect on the acceptance of mental causation in science, philosophy and in many areas of clinical practice. Biomedical accounts typically translate the effects of mind into the effects of brain functioning, for example, explaining mind/body interactions in terms of the interconnections and reciprocal control of cortical, neuroendocrine, autonomic and immune systems. While such accounts are instructive, they are implicitly reductionist, and beg the question of how conscious experiences could have bodily effects. On the other hand, non-reductionist accounts have to cope with three problems: (1) The physical world appears causally closed, which would seem to leave no room for conscious intervention. (2) One is not conscious of one's own brain/body processing, so how could there be conscious control of such processing? (3) Conscious experiences appear to come too late to causally affect the processes to which they most obviously relate."

As to the problem (1), it is thus clear that the idea of FIS is an attempt to make a theory where the physical universe as classically understood is opened theoretically by adding the concept of information that helps to explain how matter self-organize to life into the evolution of the universe and how communication is possible. This is a great step forward, but the theory of information does not really include a theory of the "inner aspects of mind and emotion" and its causal effects on the body on animal level not to speak of human consciousness level. If one believes that our conscious understanding of messages is relevant for a theory of communication then a systems and cybernetics based theory like that of autopoiesis even in Luhmann's version needs a theory of signification [26, 32]. As to the problem (2) in the quote above, then we do know from bio-feedback and yoga that we can become aware of our own bodily processes and control them. But we do not know how. Biosemiotics offers to explain these processes as endosemiotic. That leads us to (3) referring to the well known experiments showing that decisions of actions seem to be made on a level below consciousness and a few seconds before we become aware of them. Consciousness seems to be only the tip of the iceberg. But even if this means that we do not have a completely independent free will initiating things, then we still have a "free won' $t$ " that can say no to some of our impulses, and that does not rule out that logical thinking can initiate decisions moving the body.

\section{The Problem of Meaning}

Thus my main dissatisfaction with most of the theoretical offers within FIS is that it is not possible to have a theory of information, cognition and communication without a concept of meaning. Classical logic with its content-free symbols getting their content from a truth table is not a sufficient framework for understanding cognition and communication [3-4].

Meaning is mostly related to life, mind and consciousness, and usually not considered relevant in the chemical and physical realm. Following this we have to admit that it is not only a question of reductionism versus holism or general system theory but that FIS also has a "two-cultures" problem with theoretical explanations based on science and technology on one side, and humanities including philosophy on the other. Some of the problems are: 
1. Classical science still seems to harbor the general aim of explaining biology chemically, and chemistry physically.

2. But in chemistry we clearly see formal causation and information processes. Se for instance Kauffman's [23] work on auto-catalytic closure.

3. Chemical processes and structures can describe and explain crucial aspects of the physiological structure and processes of the nervous system necessary for first person experiences, but the chemistry cannot describe the experiences, which are not chemical as such. Further many biologists would argue that even the function of an organ cannot be described sufficiently without refereeing to its biological purpose.

4. If mind did not 'fall from the sky' then it developed through evolution. Still, to this day, 'mind' is completely outside the explanatory powers of physics, chemistry and biology as they are understood in mainstream science [1].

5. A concept of information built on a Wienerian classical cybernetic foundation, combining a version of the statistical formulation of information and entropy with thermodynamics, will, in my opinion, not solve any problems, but only obscure the foundation problems we have in the sciences. See my analysis of Bateson's work [1-3].

It is my hope that the biosemiotic theory of meaning and mind can integrate classical scientific thinking, the functionalistic thinking of systems and cybernetics with the evolutionary framework and the phenomenological analysis of mind as found in Merleau-Ponty [28]. It is a great challenge, however necessary to overcome for the sake of our culture.

In one of our exchanges at the FIS internet conference 2002-2003, Jerry Chandler (personal communication), very succinctly stated the fundamental challenges in our discussion of biosemiotics. He wrote:

"The issue of (bio)semiotics opens another avenue that was scarcely explored here. Currently, two primary sets of symbols are used in the natural sciences. One set of symbols consists of traditional logical and mathematical symbols and represent abstractions. Chemical symbols consist of representations of unique forms of matter and are used for the partially abstract natural sciences. Chemical symbols form a basis for the synthesis of matter and are used in molecular biology to communicate the structures of biomolecules and to describe biological signaling processes, internally within the organism, among organisms and between the organism and its ecoment. If (bio)semiotics is to become established as a source of description of biological and biomedical information, how will it establish logical consistency with either of the two existing symbol sets? Would a (bio)semiotic symbol set bridge the relations between chemical symbols and mathematical symbols? What within the current values and philosophies of the scientific communities, would motivate the creation and acceptance of a third symbol set for (bio)semiotics? Among the four terms (semiotics, information, communication, and meaning), the issue of the meanings of a symbol set may be the most difficult. Indeed, the specific meaning assigned to a specific symbol is often intertwined with preexisting conceptualizations of emergence, history, philosophy, culture and related structural processes." 
I believe that the biosemiotics that Sebeok, see for instance [36-37], developed on a Peircian theoretical background can be worked out as a framework integrating the various ontological levels of description. See for instance Deely [12] and Nöth [30-31], who each contribute to such a framework still debating the question of physico-semiotics [12, 13, 14]. Hoffmeyer and Emmeche [18] have further added a new level to the development of biosemiotics. For another important contribution see for example also Hoffmeyer [20-21], Deacon [15], Brier [6] and Emmeche [16].

Within such a framework wee further need to develop a theory of levels and types of causality. Velmans -although I do not support his attempt at solution- states part of the problems very clearly in his paper [40]:

"Within conventional medicine, physical $\rightarrow$ physical causation is taken for granted. Consequently, the proper treatment for physical disorders is assumed to be some form of physical intervention. Psychiatry takes the efficacy of physical $\rightarrow$ mental causation for granted, along with the assumption that the proper treatment for psychological disorders may involve psychoactive drugs, neurosurgery and so on. Many forms of psychotherapy take mental $\rightarrow$ mental causation for granted, and assume that psychological disorders can be alleviated by means of 'talking cures', guided imagery, hypnosis and other forms of mental intervention. Psychosomatic medicine assumes that mental $\rightarrow$ physical causation can be effective ('psychogenesis'). Consequently, under some circumstances, a physical disorder (for example, hysterical paralysis) may require a mental (psychotherapeutic) intervention. Given the extensive evidence for all these causal interactions ..., how are we to make sense of them?"

My take is to place the informational interactions between the physical and the biological level of reality and leave the theory of meaning to semiotics [9]. Everything exists in relations, but although you can understand them all within a semiotic framework with Nöth [31], I do not find it useful to call all relations semiotic; some are better called proto-semiotic as for instance the informational. I am inspired by a systems theory of developing hierarchies and therefore different kinds of causality. To begin with I want to distinguish between:

1. Efficient causality, which I relate to the physical level's exchange of force and energy between masses (part of Peirce's Secondness).

2. Formal causality, which I relate to informational and signal exchange through pattern fitting. It is a key-lock fitting with no intentionality. It is well described in cybernetics. This is protosemiotic interaction.

3. Final causality, where the goal is influencing the result. At the semiotic level, it is through more or less unconscious motivation and drive (teleonomy), and on the linguistic level, it is conscious intension.

I thus see information as a kind of formal cause working through pattern-fitting. As there is no manifest individual mind involved I will not call it pattern recognition. Meaning is communicated through sign games based on -at least some weak form of- intentionality even in animals and as final causes at the level of linguistic self-conscious free will; you might talk of existential goal-directed causes. 'Sign games' [3] is my term for what animals have, when seen in relation to the human 'language games' [5]. 


\section{Mind and Reality}

The quantum vacuum fields are our closest candidates to a foundational reality and they are only described physicalistic. A lot of researchers are trying to build theories of consciousness on quantum field theory. I think they will fail -and we will all fail- if we do not address the ontological and epistemological foundation of mind and meaning. I do not believe that life and mind can be adequately described by mechanistic models and communicative interaction based on energy-based efficient causality. I do not think that information science will 'do the trick' either. Therefore I think we must look a theory for allowing meaning and mind as part of foundational reality. That is why I am working with a Peircian based biosemiotics, combined with a systems and cybernetic view with ontological levels, and a concept of emergence following Emmeche et al. [18]. This whole framework looks as a good candidate to start with.

From an evolutionary view you will have to acknowledge that mind has emerged from nature. Thus a metaphysics that allows for this to happen is required. It seems that a mechanistic view, claiming that basic reality is simple, mathematical and deterministic, is contradictory then to an evolutionary theory of mind. Complexity theory is one step on the way to a better explanation, and information science on this basis takes it one step further when combined with theories of self-organization and closure [26, 27]. But still we somehow need to allow for mind and qualia to be part of that basic reality.

This is what Peirce does. He makes them immanent in Firstness thus making it possible for them to emerge and manifest more and more through the course of evolution, self-organization and autopoiesis. In Peirce's triadic philosophy, where the three categories work according to the 'law of mind' there is an inner aspect of Firstness (pure feeling) in matter. This is, thus, immanent in all things but it does not develop into genuine signs before organized into living cells. Thus Peirce is hylozoist. Matter is alive inside (with the pure feeling of Firstness). Thus the world is bound together, not by an ideal potential pattern as in Aristotle, but by a continuum (plenum) with pure feelings, spontaneity and the law of mind's tendency to take habits and become effete. Matter is effete mind, says Peirce [35].

I share with Peirce a belief of a basic spontaneity of nature at the basis of existence. This seems also to be the starting point for Nielsen's [29] random dynamics. This basic spontaneity can also be seen as the prerequisite for the possibility of a free will in humans, which scientists who base their thinking on a classical determinism would have to deny.

\section{The Role of Information}

I choose to see information then, as we use the concept in the sciences, to be proto-semiotic and tied to the level of formal causation. What is usually called information processes on the level of cells I acknowledge as sign processes or sign games. Language games we only see in humans and it is connected to social-linguistic self-consciousness. The 'physical universe' can only be considered closed if it encompasses mind and its evolution. Thus mind will be a part of the natural sciences but on a new philosophical foundation. Information and sign games are still a part of human messages in 
language $[8,9]$. Thus human communication has at least these three levels: informational, semiotical and socio-linguistic.

Not everything is information or signs. Because if all objects are signs and all signs are objects then I cannot see how the difference between representamen and object can be upheld. Then the triadic sign connecting representamen (primary sign) with the object and the interpretant in semiotics collapses. There must be a dynamical object 'out there' that is not a sign, which a sign through semiosis and the evolution in the semiotic web moves towards, or else the truth concept will disappear: this is how I understand Peirce. (This is a discussion with Deely's conception of physico-semiosis and through the conference with Edwina Taborsky. Both hold a more radical form of semiotics -a form of pansemiotics- than I do. My view seems to be closer to Nöth's. See my Paper for the second Biosemiotic Gatherings in Tartu 2002: Third Culture: Cybersemiotic's inclusion of a Biosemiotic Theory of Mind, in process).

We cannot give up the objective resistance of forces and willpower (that is Peirce's Secondness) and the regularity and stability coming form the natural laws or regularities in nature (Peirce's Thirdness). My problem is that if we cannot have Secondness and Thirdness in nature without them being signs then all there is in the world is signs and there are no objects to refer to. Laws of nature in themselves just are. They are not signs for us. But their description is. You can choose to see them as signs for the universe or Cosmos. Then you have to work with very different levels of semiosis depending on who is creating the interpreter. That is acceptable, but it seems more useful to work from a human social and living systems perspective first.

I would prefer an interpretation where the living systems are the universe' way of becoming aware of itself. Because here Firstness through the law of mind and its tendency to take habits not only unites with Secondness and Thirdness, but self-organizes in autopoietic closure and thereby creates individuals with an interest to preserve their own organization.

From a Peircian framework you have to admit that the universe is permeated with Firstness, which is not the same as human awareness, though it is the origin of it. We may all be one in the Firstness of the pure feeling of mind at the deepest level of existence, but the world is still there.

I suggest combining the Peircian objective idealistic pragmatic and evolutionary metaphysical framework with a systemic and cybernetic-autopoietic view as the one Luhmann [24-26] has produced, which avoids both pan-informational and pan-semiotic frameworks. It is the only one I can see possesses this complexity [8-10]. To this, one must add or integrate the concept of abduction, the third of inference methods beyond deduction and induction, as it is crucial for the understanding of how semiosis function in signification and interpretation beyond classical logic.

\section{Abduction as a Meaningful Rationality}

Abduction is very central to Peirce's theory of semiotics and logic. Abduction is not purely driven by classical logical inferential power or determinism. Abduction is -as most inferences done in daily life- always done on a basis of too little knowledge. But it is the main function in perception and 
thinking that makes sense of things through the creation of a sign relation. Thus abduction has an important function in creating meaning. From our present information-based cognitive theories of intelligence, information and cognition we cannot grasp this function. We know it bears on context and how this context is seen by the observer (motivation and intentionality) through the interest with which he or she enters it. The biological, psychological and social relations and their history and relations to the habits of nature and society are important, and therefore factors shaping the process of perception. The semiotic and the linguistic levels of communication all influence the process. But it is in the end still based on a combination of biological determination -the conservation of the organization of the living partly based on genes plus the individual way it constructs its 'signification sphere' (Umwelt), and the free will of the individual.

The symbols of classical logic are in themselves supposed to be meaningless. Content and meaning comes from what you apply them to. Contrary to this, Peirce sees logic as evolving from signification and therefore always being in a meaningful context. I think that it is a great advantage of his theory. Logic does not become an inhuman meaningless static ground pattern in human intelligence and in the profound order of Nature, as seen in both Plato and Aristotle, still seeming to be the metaphysics of much classical physics and analytic philosophy. This view seems inherited in much information science also. Instead Peirce sees it as part of a dynamical process of the evolution of living intelligence. Information can then be seen as one of the first levels in this development.

\section{Information and the Pluralism of Reality}

To summarize, I thus want to develop an informational theory accepting several 'levels of existence' [18]. When talking about nature, I think we should distinguish between:

1. An entangled form of causality on the quantum level. This is the most abstract expression of mind. It is from this level that 'virtual particles' jump in and out of manifest existence. It is also from here that the mystical 'entanglement' functions as what the physicists call 'ghostlike causal connection' beyond the time and space limits of general relativity.

2. A physical-energetic causality on the physical level (as described in physics as exchange of energy).

3. An informational-signal organizational causality in dissipative structures, cybernetic machines and on the chemical level.

4. A semiotic causality in living systems.

5. Finally, a linguistic communicative causality in human conscious and social systems.

The scientific subject areas and their findings are thus conserved and the place of information theory as a new level, understanding the organization processes of complicated dynamical systems is also conserved.

But the scientific and informational theory is now placed in the broader Cybersemiotic framework that combines Peirce triadic semiotics with systemic and cybernetic views including autopoiesis and 
second order cybernetics. Let me briefly expand the explanation of the levels seen from the Cybersemiotic framework:

1. The first level of quantum vacuum fields entangled causality is not considered physically dead as usually done in physicalistic physics. Cybersemiotics conceives it as a part of Firstness, which also holds qualia and pure feeling. Although physicist may be bothered by this new metaphysical understanding of this level of reality, they cannot claim that there is no room for new interpretations, because physics has a complete understanding of it. On the contrary, this is one of the most mysterious levels of reality we have encountered, and its implications have been discussed since the 1930's and were central in the disputes between Bohr and Einstein and now the entanglement is attempted exploited for the possibility of teleportation.

2. The second level of efficient causation is clearly what Peirce describes as Secondness. This realm is ontologically dominated by physics as classical kinematics and thermodynamics. But for Peirce it is also the willpower of mind.

3. The third level of information is where the formal causation manifests clearly and where the regularities and Thirdness becomes crucial for interactions through stable patterns. This level is ontologically dominated by the chemical sciences. This difference in ontological character may be one of the keys to understand the differences between physics and chemistry. It is not only a matter of complexity but also of organization and type of predominant causality.

4. On the fourth level, where life has self-organized, the actual semiotic interactions emerge. First internally in multi-cellular organisms as 'endosemiotics' [39] and between organism as 'sign games' [3].Thus, this framework -based on biosemiotics- points out that the informational concept may be useful at the chemical level of analyzing life, but it is not sufficient to capture the communicative, dynamic organizational closure of living systems. This is one of the reasons why Maturana and Varela [27] do not want to use the information concept in their explanations of the dynamics of life and cognition $[3,19]$. But they do not use a semiotic either.

5. Finally on the fifth level with syntactic language games, human self-consciousness emerges and with that rationality, logical thinking and creative inferences (intelligence). Intelligence is closely connected to abduction and conscious finality. Abduction is crucial to signification. It is the ability to see something as a sign for something else. This something else has to be a habit of nature. Some kind of regularity or stability in nature that the mind can recognize as somewhat lawful is necessary for it to be a fairly stable eigen value [17] in the mind (an interpretant).

This is, in essence, the five-leveled Cybersemiotic framework I propose for FIS.

\section{References}

1. Brier, S. Information and consciousness: A critique of the mechanistic concept of information, in Cybernetics \& Human Knowing 1992, 1(2/3), 71-94.

2. Brier, S. A Cybernetic and Semiotic view on a Galilean Theory of Psychology in Cybernetics \& Human Knowing 1993, 2(2), 31-45. 
3. Brier, S. Cyber-semiotics: On autopoiesis, code-duality and sign games. In bio-semiotics, Cybernetics \& Human Knowing 1995, 3(3), 3-25.

4. Brier S. The Cybersemiotic Explanation of the Emergence of Cognition: The Explanation of Cognition Signification and Communication in a Non-Cartesian Cognitive Biology. Evolution and Cognition 1998, 4(1), 90-105.

5. Brier, S. Biosemiotics and the foundation of cybersemiotics. Reconceptualizing the insights of Ethology, second order cybernetics and Peirce's semiotics in biosemiotics to create a nonCartesian information science, Semiotica 1999, 127(1/4), 169-198. Special issue on Biosemiotics.

6. Brier, S. Cybersemiotics and Umweltslehre, Semiotica 2001 134(1/4), 779-814.

7. Brier, S. Ecosemiotics and Cybersemiotics, Sign System Studies 2001, 29(1), 107-120.

8. Brier, S. Intrasemiotics and Cybersemiotics, Sign System Studies 2002, 30(9), 113-127.

9. Brier, S. The five-leveled Cybersemiotic Model of FIS (Best paper award in its session), Trappl, R. (ed.): Cybernetics and Systems 2002, 1, Austrian Society for Cybernetic Studies. 2002, 1, 197-202.

10. Brier, S. Varela's Contribution to the Creation of Cybersemiotics: the calculus of selfreference, Cybernetics \& Human Knowing 2002, 9(2), 77-82.

11. Brier, S. The integration of Second Order Cybernetics, Cognitive Biology (Autopoiesis), and Biosemiotics, Cybernetics \& Human Knowing 2003, 10(1), 107-110.

12. Deeley, J. Basics of Semiotics, Bloomington, Indiana University Press, 1990.

13. Deely, J. Physiosemiosis and semiotics. In (eds. Spinks, C. W and Deely J) Semiotics, Peter Lang, New York, 1998.

14. Deely, J. Physiosemiosis in the semiotic spiral: A play of musement. Colloquium. Sign system Studies 2001, 29(1), 27-48.

15. Deacon, T.W. The Symbolic Species: The Co-Evolution of Language and the Brain. New York: Norton, 1997.

16. Emmeche, C. Defining Life as a Semiotic Phenomenon. In Cybernetics \& Human Knowing, 1998, $5(1), 33-42$.

17. Foerster, H. von. Observing Systems, (The Systems Inquiry Series). California, USA: Intersystems Publications, 1984.

18. Emmeche, C.; Køppe, S; Stjernfelt, F. Explaining Emergence; Towards an Ontology of Levels. In Midgley, G. (ed): System Thinking, Vol. 1, General System Theory, Cybernetics and Complexity, Sage Publications, London., 2003, 141-170. Originally in Journal for General Philosophy of Science 1997, 28, 83-119.

19. Hayles, N.K. How we became posthuman: Virtual bodies in cybernetics, literature, and informatics, The University of Chicago press, Chicago and London 1999.

20. Hoffmeyer, J. Sign of Meaning in the Universe, Indiana University Press, Indiana, USA, 1997.

21. Hoffmeyer, J. "Surfaces inside surfaces”, Cybernetics \& Human Knowing 1998, 5(1), 33-42. 
22. Hoffmeyer, J.; Emmeche, C. Code-Duality and the Semiotics of Nature in M. Anderson and F. Merrell (eds). On Scientific Modeling, New York: Mouton de Gruyter, 1991, 117-166.

23. Kauffman, S. At Home in the Universe, Oxford University Press, 1995.

24. Luhmann, N. Essays on Self-Reference, New York: Colombia University Press 1990.

25. Luhmann, N. Zeichen als Form. In Baecker, D.: Probleme der Form, Suhrkamp, Frankfurt am Mein, 1993, 45-69.

26. Luhmann, N. Social Systems. Stanford, CA: Stanford University Press, 1995.

27. Maturana, H.; Varela, F. Autopoiesis and Cognition: The realization of the Living, Reidel, London, 1980.

28. Merleau-Ponty, M. Phenomenology of Perception, London: Routledge and Kegan Paul, 1958.

29. Nielsen, H.B. Random Dynamics and Relations between the Number of Fermon Generations and the Fine Structure Constants. Nielsen (Bohr Inst.). NBI-HE-89-01, Jan 1989. 50pp. Talk presented at Zakopane Summer School, May 31 - Jun 10, 1988. Published in Acta Phys.Polon, 1989, B20, 427.

30. Nöth, W. Protosemiosics and physicosemiosis, Sign System Studies 2001, 29(1), 13-26.

31. Nöth, W. Semiotic Machine. Cybernetics and Human Knowing 2002, 9(1), 3-22.

32. Ort, N.; Marcus, P. Niklas Luhmann:Sign as Form - A Comment, Cybernetics \& Human Knowing 1999, 6(3), 39-46.

33. Peirce, C.S. Collected Papers vol. I-VIII. (eds.) Hartshorne and Weiss. Cambridge MA: Harvard University Press. CD-ROM version from Past Masters, 1931-1958.

34. Prigogine, I. and Stengers, I. Order Out of Chaos: Man's New Dialogue with Nature New York: Bantam Books, 1984.

35. Santaelle Braga; L. Matter as effete mind" Peirce's synechistic idea on the semiotic threshold, Sign System Studies 2001, 29(1), 49-60.

36. Sebeok, T. Contributions to the Doctrine of Signs. Bloomington: Indiana University, 1976.

37. Sebeok, T. The Sign \& Its Masters. Sources in Semiotics VIII. New York: University Press of America, 1989.

38. Uexküll, J. von (1934). A Stroll through the Worlds of Animals and Men. A Picture Book of Invisible Worlds. In Schiller, Claire H. (ed.) (1957): Instinctive Behavior. The Development of a Modern Concept, New York, International Universities Press, Inc., 1957, 5-80.

39. Uexküll, Thure von; Geigges, W.; Herrmann J.M. Endosemiosis, Semiotica 1993, 96(1/2), 5-51.

40. Velmans, M. How could Conscious Experience Affect Brains? Journal of Consciousness Studies 2002, 9(11), 3-29.

\section{Note}

${ }^{1}$ The present text is a short overview of my viewpoints stated in the context of months of discussions on the FIS net conference. The article thus stresses where my views differ from most discussants arguing about the relevance and new perspective of this thinking. The article is very short 
for such a complicated matter and I have therefore put references to those of my articles where further articulations of the particular view can be found. A book collecting the whole argument around and a model of Cybersemiotics is in review at the moment.

(C) 2003 by MDPI (http://www.mdpi.org). Reproduction for noncommercial purposes permitted. 